\title{
Detection of Spatio-Temporal Changes of Norway Spruce Forest Stands in Ore Mountains Using Airborne Hyperspectral Imagery
}

\author{
Jan Mišurec ${ }^{1,2, *}$, Veronika Kopačková ${ }^{1}$, Zuzana Lhotáková ${ }^{3}$ and Jana Albrechtová ${ }^{3}$ \\ 1 Czech Geological Survey, Klárov 3, Prague 1, Czech Republic; E-Mails: jan.misurec@geology.cz; \\ veronika.kopackova@geology.cz \\ 2 Charles University in Prague, Faculty of Science, Department of Applied Geoinformatics and \\ Cartography, Albertov 6, Prague 1, Czech Republic \\ 3 Charles University in Prague, Faculty of Science, Department of Experimental Plant Biology, \\ Viničná 6, Prague 1, Czech Republic; E-Mails: zuza-lhotak@seznam.cz, \\ jana.albrechtova@natur.cuni.cz; \\ * Author to whom correspondence should be addressed; E-Mail: jan.misurec@geology.cz; \\ Tel.: +420-257-089-511
}

Published: 22 June 2015

\begin{abstract}
The Ore Mountains are an example of the region that suffered from severe environmental pollution caused by long-term coal mining and heavy industry leading to massive dieback of the local Norway spruce forests between the 1970's and 1990's. The situation became getting better at the end of 1990's after pollution loads significantly decreased. In 1998 and 2013, airborne hyperspectral data (with sensor ASAS and APEX, respectively) were used to study recovery of the originally damaged forest stands and compared them with those that have been less affected by environmental pollution. The field campaign (needle biochemical analysis, tree defoliation etc.) accompanied hyperspectral imagery acquisition. An analysis was conducted assessing a set of 16 vegetation indices providing complex information on foliage, biochemistry and canopy biophysics and structure. Five of them (NDVI, NDVI $705, \mathrm{VOG}_{1}, \mathrm{MSR}$ and TCARI/OSAVI) showing the best results were employed to study spatial gradients as well as temporal changes. The detected gradients are in accordance with ground truth data on representative trees. The obtained results indicate that the original significant differences between the damaged and undamaged stands have been generally levelled until 2013, although it is still possible to detect signs of the previous damages in several cases.
\end{abstract}

Keywords: forest health; tree physiological status, hyperspectral imagery, Norway spruce, Ore Mountains 


\section{Introduction}

Forests belong to most crucial terrestrial ecosystems. However, they have recently faced increasing pressure not only in terms of human needs of wood and other resources, but also worsening of environmental conditions mainly by human industrial activities. The concerns of forest health status lead to numerous remote sensing applications focusing on monitoring the actual level of forest damage using multispectral data like Landsat TM/ETM+, e.g. [1-2]. Significant advances have been made with the use of the first generation of airborne hyperspectral sensors enabling identification of not only significant forest damage, but also the very initial phases of vegetation stress. [3-4].

The main aim of this paper is to assess spatio-temporal differences between the particular Norway spruce stands located in the western and central parts of the Ore Mts. using several vegetation condition sensitive vegetation indices extracted from the ASAS and the APEX imagery in combination with the set of ground supportive data. We would like to answer the question whether there is currently any significant difference in tree physiological status between the originally damaged and subsequently recovered stands at central Ore Mts. and the stands which have never been seriously damaged located in the western Ore Mts.

\section{Methods}

Our study took part in the Ore Mountains (western Bohemia), which is one example of the region which suffered by severe environmental pollution caused by coal mining and heavy industry leading to massive dieback of the local Norway spruce forests between 1970 and 1990. Two temporal hyperspectral and ground-truth datasets were analyzed to study temporal changes of selected forest stands. First dataset represents ASAS (Airborne Solid-state Array Spectrometer) imagery and extensive in-situ data on forest biochemistry and biophysics acquired at the end of Norway spruce forest dieback phase [4-5]. A new hyperspectral image (Airborne Prism Experiment - APEX) as well as in-situ data were acquired in 2013 to assess forest physiological status after 15 years of regeneration.

\subsection{Study area}

The study was performed at two locations situated in Ore Mountains region in Western Bohemia. Přebuz, situated in the western part of the Ore Mountains, has not been significantly affected by air pollution and the related phenomena and local forests show historically stable conditions with no or light damage level. Kovářská, situated in central Ore Mountains, suffered historically much higher loads of $\mathrm{SO}_{2}, \mathrm{NO}_{\mathrm{x}}$ and $\mathrm{PM}_{10}$ [6]. Local forests showed moderate to high level of damage at the end of 1990-ies. The stands have been recovered since 2000 and currently show no visual damage symptoms. 
Figure 1. Norway spruce stands sampled at Přebuz and Kovářská localities in 1998. Background map ${ }^{\circledR} \check{C} \mathrm{UZK}$

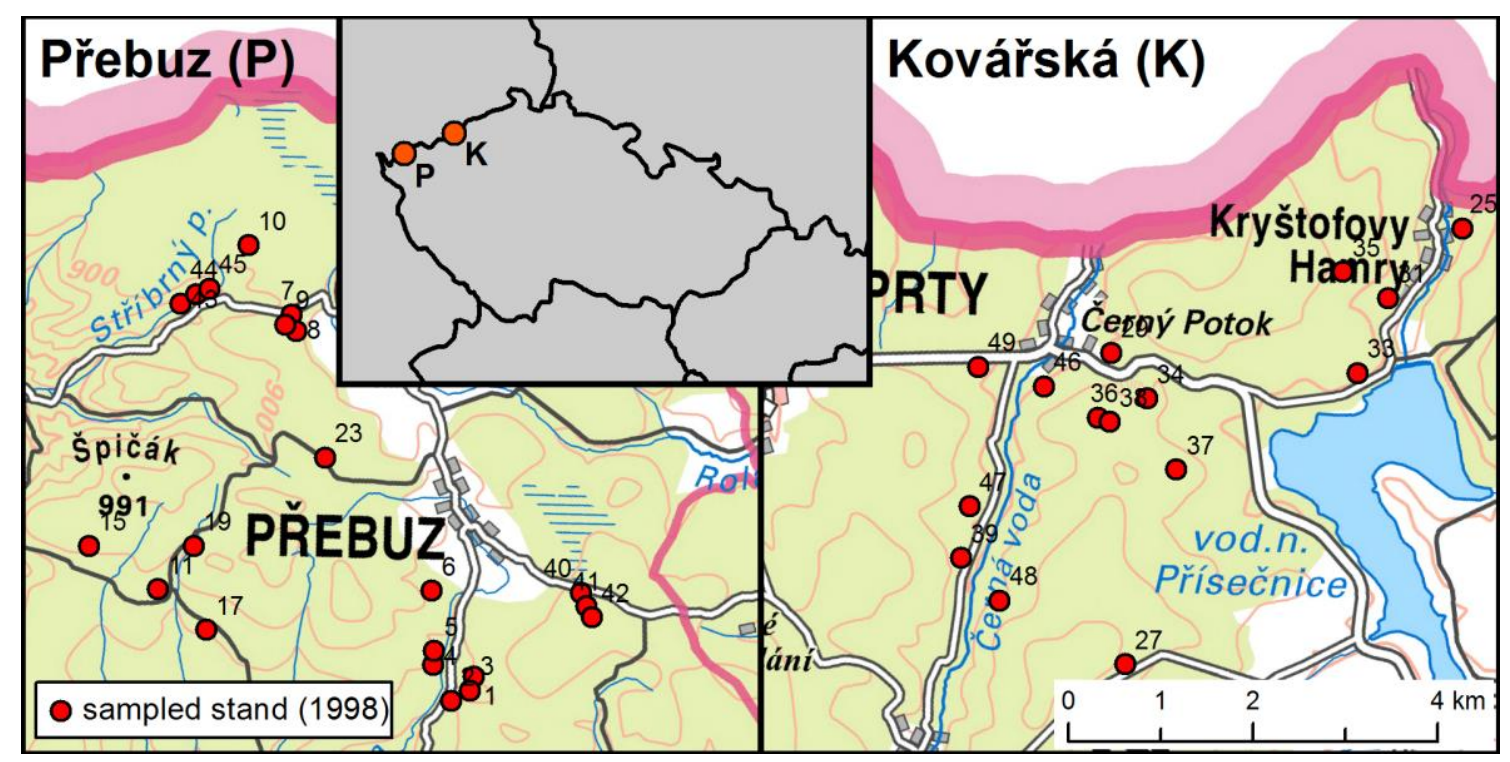

\subsection{Airborne hyperspectral data}

ASAS data were acquired between $20^{\text {th }}$ August and $1^{\text {st }}$ September 1998 consisting of 62 spectral bands (with FWHM ca. $10 \mathrm{~nm}$ ) covering the spectral interval from 410 to $1032 \mathrm{~nm}$. However, only the bands between approx. $550-850 \mathrm{~nm}$ were practically usable for the further analyses due to poor spectral performance of the sensor in the VIS-B and far NIR regions. The original ground spatial resolution of this dataset was $1.5 \times 2.0 \mathrm{~m}$.

The raw data were radiometrically calibrated and finally transformed to at-surface reflectance using the $6 \mathrm{~S}$ atmospheric correction code as well as the in-situ ground level spectra of two selected calibration targets (dark asphalt and bright lime) taken by GER-2500 field spectroradiometer.

APEX data were acquired on $6^{\text {th }}$ September 2013 consisting of 286 spectral bands (with FWHM ca. $7 \mathrm{~nm}$ ) covering the spectral interval between approx. 430 and $2450 \mathrm{~nm}$. The original ground spatial resolution of the dataset was $2.0 \mathrm{~m}$.

Supportive calibration/validation ground campaign was organized simultaneously with the acquisition of hyperspectral imagery. Surface level spectra of several calibration and validation targets of adequate spatial extent and homogeneity were taken by ASD Fieldspec- 4 spectroradiometer. The targets included water bodies $(2 x)$, asphalt $(3 x)$, concrete tiles $(4 x)$, bare soil/sand $(1 \times)$, fresh grass $(2 \times)$ and dry grass $(1 \times)$.

Radiometric calibration, smile effect removal, geometric and atmospheric correction of the APEX dataset was performed by VITO. Radiometric calibration was conducted using the APEX Calibration Home Base data [7]. Geometric correction was performed using the data from GPS/IMU, boresight corrections and $5 \mathrm{~m}$ grid lidar-based digital elevation model. Atmospheric correction was conducted using the CDPC module [8] based on MODTRAN-4 radiative transfer code followed by algorithm described by [9]. 
Figure 2. (a) Hypercubes constructed from the ASAS data covering 410 - $1032 \mathrm{~nm}$ spectral range (A) and APEX data (B) covering 430 - $2450 \mathrm{~nm}$ range.
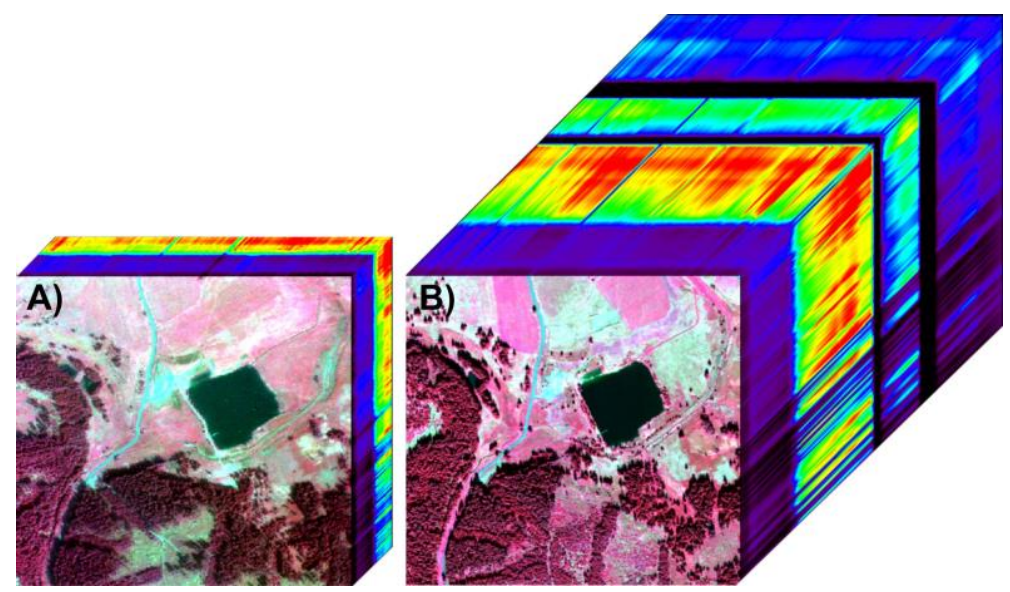

\subsection{Ground supportive campaign}

The ground supportive campaign was organized simultaneously with the ASAS data acquisition in late August 1998. In total, 38 even aged mature Norway spruce stands (21 at Přebuz and 17 at Kováŕská sites) were selected for evaluation of tree physiological status using five-grade damage class scale as described in Table 1. The classification scheme is based on defoliation degree and presence of chlorosis rising from the practice used in the Czech Republic on that time [4]. In addition, five trees were selected at each stand for needle sampling to determine content of photosynthetic pigments (chlorophylls and carotenoids). The foliar pigments content was determined spectrophotometrically according to [10] after extraction in dimethylforamide according to [11] and normalized by dry sample weight $\left(\mathrm{mg} \cdot \mathrm{g}^{-1}\right)$. All the sampled trees fallen within the area of $30 \times 30 \mathrm{~m}$ whose centroid was localized by differentially corrected GPS [4].

In 2013, a new ground campaign was organized simultaneously with the APEX data acquisition. Eleven Norway spruce stands were selected for a detailed study, from which 8 coincided with the stands selected during the 1998 campaign (stands $\mathrm{P}_{9}, \mathrm{P}_{10}, \mathrm{P}_{11}, \mathrm{P}_{40}, \mathrm{~K}_{25}, \mathrm{~K}_{37}, \mathrm{~K}_{46}$ and $\mathrm{K}_{47}$ ). Similar sampling design was applied in this case using five sampling trees per stand for foliar pigments content assessment. All stands were classified into $\mathrm{DC}_{0}$ and $\mathrm{DC}_{1}$ classes at both Přebuz and Kovářská sites as they did not show any severe symptoms of damage.

Table 1: Forest health status classification scheme used during the campaign in 1998 adopted from [4].

\begin{tabular}{|c|l|c|c|c|c|}
\hline \multirow{2}{*}{ damage class } & \multirow{2}{*}{ vitality status } & \multicolumn{2}{|c|}{ canopy defoliation (\%) } & \multicolumn{2}{c|}{ \% of stands (1998) } \\
\cline { 3 - 6 } & & chlorosis absent & chlorosis present & Přrebuz & Kovářská \\
\hline DC0 & healthy & $0-10$ & $X$ & 55 & 0 \\
\hline DC1 & initial damage & $11-25$ & $0-10$ & 45 & 0 \\
\hline DC2 & moderate damage & $26-60$ & $11-25$ & 0 & 36 \\
\hline DC3 & heavy damage & $61-80$ & $26-60$ & 0 & 64 \\
\hline DC4 & ecosystem collapse & $81-100$ & $61-100$ & 0 & 0 \\
\hline
\end{tabular}




\subsection{Stand definition}

The Norway spruce stands defined during the 1998 field campaign were considered essential as healthy $\left(\mathrm{DC}_{0}-\mathrm{DC}_{1}\right.$; located at Přebuz area) and damaged ones $\left(\mathrm{DC}_{2}-\mathrm{DC}_{3}\right.$; located at Kovářská area) were clearly distinguished [4]. Note that no stand was classified into the $\mathrm{DC}_{4}$ class neither at Přebuz nor at Kovářská site.

The original number of stands was reduced due to several issues such as cloud coverage, timbering (stands were cut-off in the 1998 - 2013 period) etc. Some other stands were out of the extent of the ASAS dataset. Finally, 16 stands defined in 1998 could have been found in both the ASAS and the APEX datasets, 14 at Přebuz $\left(\mathrm{P}_{1}, \mathrm{P}_{2}, \mathrm{P}_{3}, \mathrm{P}_{4}, \mathrm{P}_{5}, \mathrm{P}_{6}, \mathrm{P}_{9}, \mathrm{P}_{10}, \mathrm{P}_{11}, \mathrm{P}_{15}, \mathrm{P}_{17}, \mathrm{P}_{43}, \mathrm{P}_{44}, \mathrm{P}_{45}\right)$ and 2 at Kovářská sites $\left(\mathrm{K}_{33}\right.$ and $\left.\mathrm{K}_{37}\right)$.

The forest health status analysis was performed at two levels of spatial resolution: original $(2.0 \mathrm{~m})$ considering individual tree crowns, and generalized $(6.0 \mathrm{~m})$ considering whole forest stands. The stands were defined by $30 \mathrm{~m}$ buffer zone. The pixels representing sunlit parts of Norway spruce crowns defined by Mahalanobis distance classificator were taken in into account in case of the original resolution data (Figure 3), whereas all the pixels within the defined buffers were used in case of the generalized level data.

Figure 3. Definition of the Norway spruce sampling stands in the original APEX data (A) and binary mask of the sunlit crowns (B).
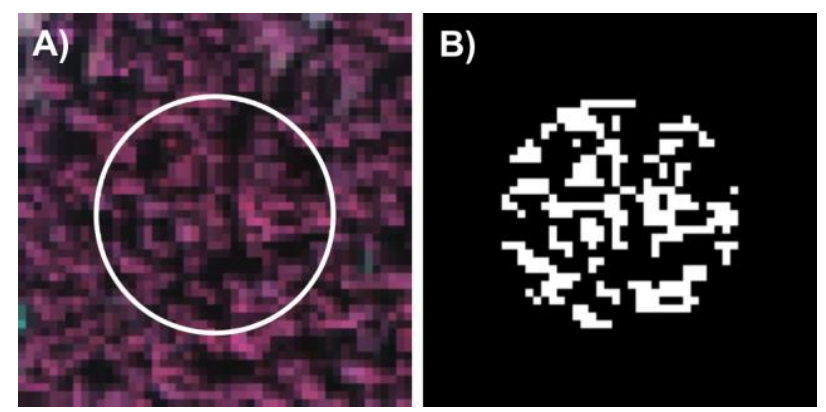

\subsection{Vegetation indices and stands separability}

In case of the ASAS dataset, only the bands between 550 - $850 \mathrm{~nm}$ were usable for further processing. This limited the number of vegetation indices (VIs) that can be calculated from these data (e.g. all the indices requiring the VIS-B bands had to be excluded). APEX data were resampled to the spectral resolution of the ASAS data prior the calculation of VIs to ensure their comparability. The vegetation indices used within this study are listed in Table 2. 
Table 2. Vegetation indices used for the spatio-temporal analysis of Norway spruce physiological status.

\begin{tabular}{|l|l|}
\hline \multicolumn{2}{|l|}{ Table 2: Vegetation indices } \\
\hline $\mathrm{NDVI}_{705}[12]$ & MCARI [19] \\
\hline VOG $_{1}$ and $\mathrm{VOG}_{2}[13]$ & TVI [20] \\
\hline REP [14] & TCARI [21] \\
\hline NDVI [15] & OSAVI [22] \\
\hline RDVI [16] & TCARI/OSAVI [21] \\
\hline MSR [17] & $\mathrm{N}_{704}, \mathrm{~N}_{714}, \mathrm{~N}_{724}[4]$ \\
\hline MSAVI [18] & $\mathrm{D}_{714} / \mathrm{D}_{704}, \mathrm{D}_{724} / \mathrm{D}_{704}[4]$ \\
\hline
\end{tabular}

In the first step, a simple separability index was calculated between the healthy and damaged forest stands for the all VIs to check their sensitivity on forest damage. The SI was calculated using the following formula used in [23]:

$$
S I=\frac{\left|\mu_{h}-\mu_{d}\right|}{\sigma_{h}+\sigma_{d}}(1)
$$

where: SI is the value of separability index; $\mu_{\mathrm{h}}$ and $\sigma_{\mathrm{h}}$ are mean and standard deviation calculated from the pixels within the healthy (undamaged) forest stands; $\mu_{\mathrm{d}}$ and $\sigma_{\mathrm{d}}$ are mean and standard deviation calculated from the pixels within the damaged forest stands.

The original values of the given VIs obtained from the ASAS dataset are not directly comparable to the ones extracted from the APEX dataset. This is mainly due to technological differences between ASAS and APEX sensors, differences in atmospheric correction applied on the ASAS and APEX datasets etc. The original VIs values were therefore normalized to allow their mutual comparability using the following formula:

$$
V I^{\prime}{ }_{x}=\frac{V I_{x}-V I_{\mu}}{V I_{\sigma}}(2)
$$

where: $\mathrm{VI}_{\mathrm{x}}$ is the normalized value of vegetation index $\mathrm{VI}$ for pixel $\mathrm{x} ; \mathrm{VI}_{\mathrm{x}}$ is the original value of vegetation index $\mathrm{VI}$ for pixel $\mathrm{x} ; \mathrm{VI}_{\mu}$ and $\mathrm{VI}_{\sigma}$ are mean and standard deviation values of vegetation index VI calculated from the all pixels representing sunlit crowns within the all buffer areas representing the selected forest stands.

\subsection{Detection of spatial and temporal differences}

Student's two-sample test was used to analyze spatial differences as well as temporal changes. In the first case we tested whether there are any significant differences in VIs values extracted from the healthy and damaged stands. In the second case, the relativized VI' values describe the relative distance of the given pixel from the global mean (calculated from all pixels). We thus analyzed whether any significant change of the relative distance to the global mean occurred at the given stand. The tests were performed at the $95 \%$ significance level $(\alpha=0.05)$. 


\subsection{Evaluation of changes in content of photosynthetic pigments}

Two physiological photosynthetic pigment markers were used as the indicators of tree physiological status: chlorophyll-a to chlorophyll-b ratio $\left(\mathrm{C}_{\mathrm{a}} / \mathrm{C}_{\mathrm{b}}\right)$ and total carotenoids to total chlorophylls ratio $\left(\mathrm{C}_{\mathrm{x}} / \mathrm{C}_{\mathrm{ab}}\right)$. Worsening of tree physiological status is usually exhibited by increase in $\mathrm{C}_{\mathrm{a}} / \mathrm{C}_{\mathrm{b}}$ ratio as chlorophyll-b is regarded to be more sensitive to vegetation stress than chlorophyll-a [24]. Similarly, stress conditions lead to increasing in $\mathrm{C}_{\mathrm{x}} / \mathrm{C}_{\mathrm{ab}}$ ratio [25].

Temporal differences in photosynthetic pigments contents and their ratios were evaluated for the stands sampled in both years (1998 and 2013) and covered by both hyperspectral image datasets. Two-way ANOVA (considering differences as significant in $\mathrm{p}<0.05$ ) was used for evaluation the differences between the localities (Přebuz and Kovářská) and the temporal changes. The differences between localities in particular years were determined by Tukey-Kramer multiple comparison test.

\section{Results}

The performed sensitivity analysis proved that majority of the used VIs is highly sensitive to vegetation health status and forest damage. The separability scores for the most sensitive indices are shown in Table 3.

Table 3: Separability scores (SI) of the five most sensitive indices for the original $(2 \mathrm{~m})$ and generalized $(6 \mathrm{~m})$ spatial resolution ASAS data.

\begin{tabular}{|c|c|c|}
\hline dataset & \multicolumn{2}{|c|}{ ASAS (1998) } \\
\hline resolution & 2 m (crown level) & $6 \mathrm{~m}$ (stand level) \\
\hline 1. & $\mathrm{VOG}_{1}: 1.87$ & $\mathrm{~N}_{714}: 1.92$ \\
\hline 2. & NDVI: 1.55 & $\mathrm{VOG}_{1}: 1.88$ \\
\hline 3. & TCARI/OSAVI: 1.52 & TCARI/OSAVI: 1.88 \\
\hline 4. & MSR: 1.48 & MSR: 1.85 \\
\hline 5. & $\mathrm{NDVI}_{705}: 1.44$ & $\mathrm{NDVI}_{705}: 1.80$ \\
\hline
\end{tabular}

Significant differences were detected for the VIs values between damaged stands located at Kovářská (central Ore Mts.) and healthy ones located at Přebuz (western Ore Mts.) in both original $(2 \mathrm{~m})$ and generalized $(6 \mathrm{~m})$ spatial resolutions of the ASAS dataset (p-values were far less than 0.01 in all cases). Moreover, these differences were detectable also in case of the APEX 2013 data although they were not as noticeable as in case of the 1998 dataset.

The temporal changes were studied using primarily the $\mathrm{VOG}_{1}$ index as it was showing high and stable sensitivity to forest damage for both considered spatial resolutions. Significant changes of the relativized VI' values were proved at major part of the studied stands except of $\mathrm{P}_{5}$ (p-value 0.28 ) and $\mathrm{P}_{17}$ (p-value 0.46).

A simple visualization was developed to facilitate interpretation of the obtained results (Figure 4). The charts show the relative distance of the particular stands (defined by local mean of the given VI) from the baselines (defined by the global mean of the given VI) in both time horizons. Four possible situations can be defined from this point of view: 
- positive stagnation (+/+): local mean of the relativized VI' values was positive in both time horizons. The given stand was above the global mean in both years.

- negative stagnation (-I-): local mean of the relativized VI' values was negative in both years. The stand was below the global mean in both years.

- recovery $(-/+)$ : local mean of the relativized VI' values was negative in 1998, but positive in 2013. The stand was below the global mean in 1998, but above the global mean in 2013.

- worsening (+/-): The given stand was above the global mean in 1998 but below the global mean in 2013.

The biochemical analysis did not prove significant differences in total chlorophyll a and b content in Norway spruce needles sampled on either locality in 1998 and 2013. Nevertheless, differences were detected in the ratios of photosynthetic pigments $\left(\mathrm{C}_{\mathrm{a}} / \mathrm{C}_{\mathrm{b}}\right.$ and $\left.\mathrm{C}_{\mathrm{x}} / \mathrm{C}_{\mathrm{ab}}\right)$. However, these differences were statistically significant only in 1998 dataset corresponding to higher degree tree and stand damage observed in central Ore Mts. (Figure 6).

Figure 4. Visualization of Norway spruce health status temporal change between 1998 and 2013 at Přebuz (P) and Kovářská (K) sites using VOG $_{1}$ vegetation index constructed for original (A) and generalized (B) spatial resolution of image data.
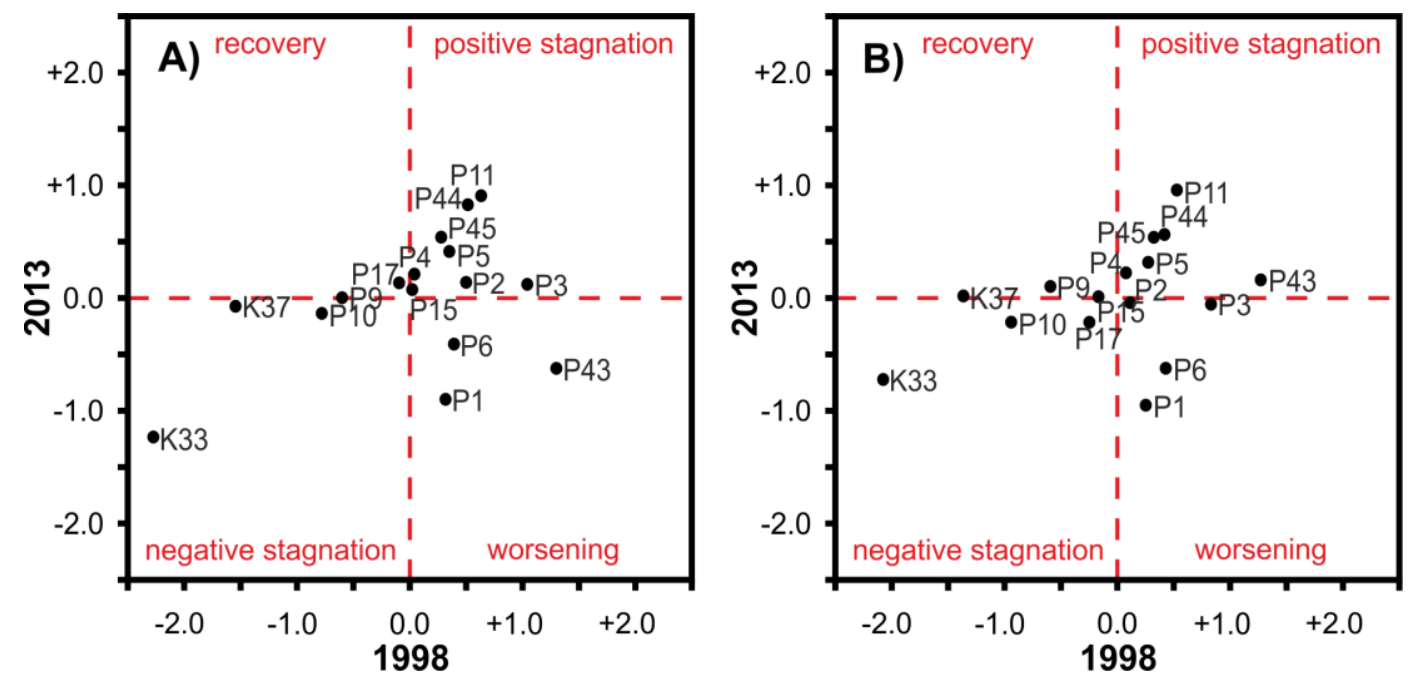

Figure 5. Spatio-temporal changes (comparison of 1998 and 2013 data for Přebuz and Kovářská sites) in the ratios of photosynthetic pigments by the Tukey-Kramer multiple comparison test: A) chlorophyll-a to chlorophyll-b ratio; B) total carotenoids to total chlorophylls ratio. Different letters above the mean/standard deviation columns correspond to significant difference at $\alpha=0.05$. 

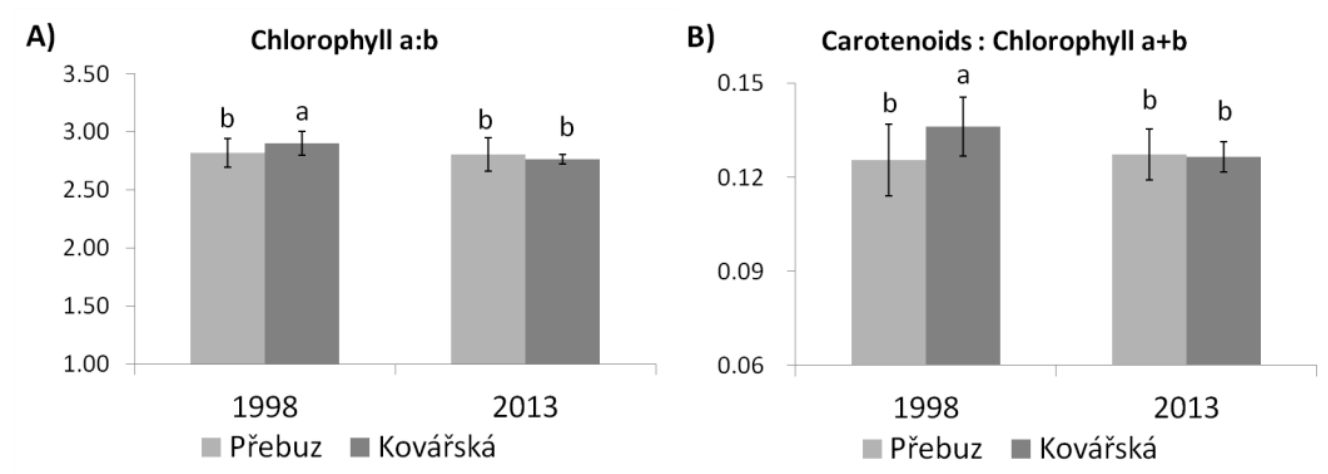

Figure 6. Relativized values of the $\mathrm{VOG}_{1}$ vegetation index calculated from the ASAS (1998) and APEX (2013) hyperspectral image data in original $2 \mathrm{~m}$ spatial resolution for $\mathrm{P}_{11}$ and $\mathrm{K}_{37}$ stands.
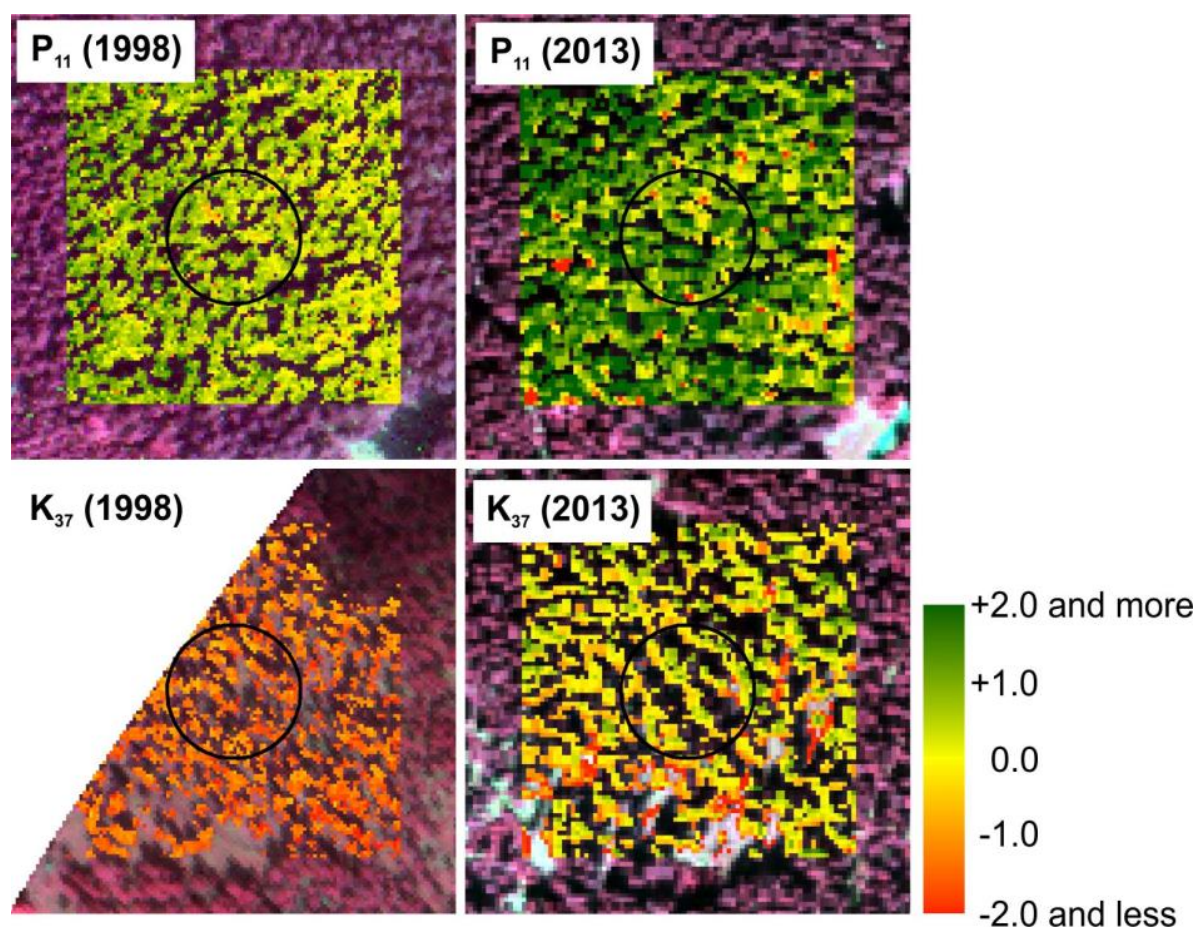

\section{Discussion}

Based on the above studied indicators of forest health status we can conclude that in 1998 significant differences were observed between damaged (central Ore Mts. - Kovářská) and undamaged (western Ore Mts. - Přebuz) stands. This result is in good agreement with the general gradient of air pollution within the Ore Mountains region due to prevailing wind direction which brought more pollution to the central and eastern parts of the Ore Mts. compared to their western part. The observed gradient of vegetation damage is also in accordance with previous studies [26, 27, 5].

In 2013, the stands at Kovářská exhibited VI' values much closer to the global mean (compared to 1998) indicating improvement of health status of the local Norway spruce forests. It demonstrates that the stands at Kovářská responded more positively to sharp decrease in air pollution loads compared to the stands at Přebuz. Nevertheless, there are still minor differences between the stands at Kovářská and Přebuz which are detectable by the majority of the used VIs. This demonstrates ability of the chosen 
VIs in detecting not only high level of forest damage, but also slight differences in physiological status, which do not have any visible symptoms (such as high defoliation level etc.).

Ratios of photosynthetic pigments are sensitive indicators of air pollution [25, 27]. The differences in $\mathrm{C}_{\mathrm{a}} / \mathrm{C}_{\mathrm{b}}$ and $\mathrm{C}_{\mathrm{x}} / \mathrm{C}_{\mathrm{ab}}$ ratios generally corresponded with the spatial gradient of forest physiological status observed by the used VIs in both compared years 1998 and 2013. In 2013, the analysis confirmed a slight improvement in Norway spruce physiological status for Kovářská stands whereas the values for western-located Přebuz stands remained the same. Thus there are currently no significant differences in physiological photosynthetic pigment markers between the studied.

\section{Conclusions}

Several of the tested VIs proved to be highly sensitive to vegetation health status and forest damage, particularly $\mathrm{VOG}_{1}$, TCARI/OSAVI, MSR and NDVI 705 . The $\mathrm{VOG}_{1}$ index was showing high and stable sensitivity to forest damage for both considered spatial resolutions (the original and generalized; 2 and $6 \mathrm{~m}$ respectively) and thus it was selected for a study of the spatio-temporal changes. Selected sensitive VIs also demonstrated ability to detect not only high level of forest damage, but also slight differences in physiological status, which do not have any visible symptoms (such as high defoliation level etc.).

Generally, we conclude that forest recovery appeared in Ore Mts. during the observed period 1998 - 2013. Regarding spatio-temporal changes in forest status, in 1998 significant differences were observed between damaged (central Ore Mts. - Kovářská) and undamaged (western Ore Mts. Přebuz) stands, while in 2013 sort of "averaging" of the health status of Norway spruce stands has been observed: surviving trees in the central part improved their health status remarkably while originally undamaged stands in the western part showed symptoms of chronic damage. Since adverse soil conditions are longer persisting and improving only slowly comparing to air conditions and pollution, forests in the Ore Mts. are still exposed to acid soil conditions. The pollution load, particularly of sulfur, was reduced tremendously, however, the acid deposition in coniferous stands in the Ore Mts. still plays an important role, particularly due to nitrate deposition, which is currently exceeding critical load in $87-90 \%$ [28]. We suppose that the full recovery of Norway spruce forest in the Ore Mountains will not occur in the nearest future due to persisting adverse soil conditions.

The presented study has character of methodical demonstration due to limited spatial extent of hyperspectral imagery acquired in 1998. Nevertheless, the obtained results seem to be promising and demonstrate great potential for further use of the proposed workflow (e.g. broader spatial area covered with multi-temporal hyperspectral data allowing more representative forest health status analysis). Higher temporal resolution of hyperspectral data (e.g. one acquisition per each vegetation season) would positively affect our knowledge on forest recovery processes. The main environmental drivers affecting forest productivity and services are currently regarded climate change together with anthropogenic pressure including air pollution [29, 30]. Since forests represent a key component in carbon cycling, the effective large-scale methods of remote sensing to detect their physiological status and capability of carbon sequestration are becoming crucially important. Our study demonstrates capability of highly sensitive VIs derived from hyperspectral data to facilitate this demand for spruce forests. 


\section{Acknowledgments}

The authors would like to thank Dr. Petya Entcheva-Campbell for providing the ASAS data and other helpful information regarding the campaign 1998. In addition, we would like to thank the all collaborators participating on ground supportive campaigns from the Faculty of Science, Charles University in Prague (1998 and 2013) and from University of New Hampshire, Durham, U.S. (1998 only). The authors wish to thank VITO's colleagues for their professionalism, mission planning and APEX data acquisition and pre-processing while maintaining the highest standards. The appreciation also goes to technicians Drahomíra Bartáková and Monika Kovářová for photosynthetic pigments determination.

The study was supported by the Ministry of Education, Youth and Sports of the Czech Republic under the grants no. LH 12097 and NPUI LO 1417 (the work of the last two authors only).

\section{Conflicts of Interest}

The authors declare no conflicts of interest as well as no direct financial profit arising from the publication of this study.

\section{References and Notes}

1. Lambert, N.; Ardo, J.; Rock, B.N. Spectral characterization and regression based classification of forest damage in Norway spruce stands in Czech Republic using Landsat Thematic Mapper data. International Journal of Remote Sensing 1995, 16, 1261-1287.

2. McDonald, A.J.; Gemmell, F.M.; Lewis, P.E. Investigation of the Utility of Spectral Vegetation Indices for Determining Information on Coniferous Forests. Remote Sensing of Environment 1998, 66, 250-272.

3. Treitz, PM.; Howarth, P.J. Hyperspectral remote sensing for estimating biophysical parameters of forest ecosystems. Progress in Physical Geography 1999, 23, 359-390.

4. Campbell, P.K.E.; Rock, B.N.; Martin, M.E.; Neefus, C.D.; Irons, J.R.; Middleton, E.M.; Albrechtová, J. Detection of initial damage in Norway spruce canopies using hyperspectral airborne data. International Journal of Remote Sensing 2004, 25(24), 5557-5583.

5. Albrechtová, J.; Rock, B.N.; Soukupová, J.; Entcheva, P.; Šolcová, B.; Polák, T. Biochemical, histochemical, structural and reflectance markers of damage in Norway spruce from Krušné hory used for interpretation of remote sensing data. Journal of Forest Science 2001, 47, 26-33.

6. Air Pollution and Atmospheric Deposition in Data, the Czech Republic. http://portal.chmi.cz/files/portal/docs/uoco/isko/tab_roc/tab_roc_EN.html (19.5.2015).

7. Gege, P.; Fries, J.; Haschberger, P.; Schötz, P.; Schwarzer, H.; Strobl, P.; Suhr, B.; Ulbrich, G.; Vreeling, W.J. Calibration facility for airborne imaging spectrometers. ISPRS Journal of Photogrammetry \& Remote Sensing 2009, 64, 387-397.

8. Biesemans, J.; Sterckx, S.; Knaeps, E.; Vreys, K.; Adriaensen, S.; Hooyberghs, J.; Meuleman, K.; Kempeneers, P.; Deronde, B.; Everaerts, J.; Schläpfer, D.; Nieke, J. Image processing workflows for airborne remote sensing. In Proceedings of the $5^{\text {th }}$ EARSeL Workshop on Imaging Spectroscopy, Bruges, Belgium, 2007, pp. 8. 
9. De Haan, J.F.; Hovenier, J.W.; Kokke, J.M.M.; Van Stokkom, H.T.C. Removal of atmospheric influences on satellite-borne imagery: a radiative transfer approach. Remote Sensing of Environment 1991, 37, 1-21.

10. Welburn, A.R. The spectral determination of chlorophyll a and b, as well as carotenoids, using various solvents with spectrophotometers of different resolution. Journal of Plant Physiology 1994, 144, 307-313.

11. Porra, R.J.; Thompson, W.A.; Kriedemann, P.E. Determination of accurate extinction coefficients and simultaneous equations for assaying chlorophylls a and b extracted with four different solvents: verification of the concentration of chlorophyll standards by atomic absorption spectroscopy, Biophysica et Biochimica Acta 1989, 975, 384-394.

12. Sims, D.A.; Gamon, J.A. Relationships between leaf pigment content and spectral reflectance across a wide range of species, leaf structures and developmental stages. Remote Sensing of Environment 2002, 81, 337-354.

13. Vogelmann, J.E.; Rock, B.N.; Moss, D.M. Red Edge Spectral Measurements from Sugar Maple Leaves. International Journal of Remote Sensing 1993, 14, 1563-1575.

14. Curran, P.J.; Windham, W.R.; Gholz H.L. Exploring the Relationship between Reflectance Red Edge and Chlorophyll Concentration in Slash Pine Leaves. Tree Physiology 1995, 15, 203-206.

15. Rouse, J.W.; Haas, R.H.; Shell, J.A.; Deering, D.W. Monitoring vegetation systems in the Great Plains with ERTS-1. In Third Earth Resources Technology Satellite Symposium 1973, 309-317.

16. Rougean J.L.; Breon, F.M. Estimating PAR absorbed by vegetation from bidirectional reflectance measurements. Remote Sensing of Environment 1995, 51, 375-384.

17. Chen, J. Evaluation of vegetation indices and modified simple ratio for boreal applications. Canadian Journal of Remote Sensing 1996, 22, 229-242.

18. Qi, J.; Chehbouni, A.; Huete, A.R.; Keer, Y.H.; Sorooshian, S. A modified soil vegetation adjusted index. Remote Sensing of Environment 1994, 48, 119-126.

19. Daughtry, C.S.T.; Walthall, C.L.; Kim, M.S.; Brown de Colstoun, E.; McMuetrey III, J.E. Estimating corn leaf chlorophyll concentration from leaf and canopy reflectance. Remote Sensing of Environment 2000, 74, 229-239.

20. Broge, N.H.; Leblanc, E. Comparing prediction power and stability of broadband and hyperspectral vegetation indices for estimating of green leaf area index and canopy chlorophyll density. Remote Sensing of Environment 2000, 76, 156-172.

21. Haboudane, D.; Miller, J.R.; Tremblay, N.; Zarco-Tejada, P.J.; Dextraze, L. Integrated narrowband vegetation indices for prediction of crop chlorophyll content for application to precise agriculture. Remote Sensing of Environment 2002, 81, 416-426.

22. Rondeaux, G.; Steven, M.; Baret F. Optimization of soil-adjusted vegetation indices, Remote Sensing of Environment 1996, 51, 375-384.

23. Tuominen, J.; Lipping, T.; Kuosmanen, V.; Haapanen, R. Remote Sensing of Forest Health, In Remote Sensing of Forest Health, Geoscience and Remote Sensing, Pei-Gee Peter Ho (Ed.), InTech, 2004, available online at: http://www.intechopen.com/books/geoscience-and-remotesensing/remote-sensing-of-forest-health. 
24. Konečná, B.; Frič, F., Masarovičová, E. Ribulose-1,5-bisposphate carboxylase activity and protein content in pollution damaged leaves of three oak species. Photosynthetica 1989, 23. 566574.

25. Siefermann-Harms, D. Light and temperature control of season-dependent changes in the $\alpha$ - and $\beta$ - carotene content of spruce needles. Journal of Plant Physiology 1994, 143, 488-494.

26. Kubíková, J. Forest dieback in Czechoslovakia. Vegetation 1991, 93, 101-108.

27. Soukupová, J.; Cvikrová, M.; Albrechtová, J.; Rock, B.N.; Eder, J. Histochemical and biochemical approaches to the study of phenolic compounds and peroxidases in needles of Norway spruce (Picea Abies L. Karst.). New Phytologist 2000, 146, 403-414.

28. Šrámek, V.; Slodičák, M.; Lomský, B.; Balcar, V.; Kulhavý, J.; Hadaš, P.; Pulkráb. K.; Šišák, L.; Pěnička, L.; Sloup, M. The Ore Mountains: Will successive recovery from lethal disease be successful? Mountain Research and Development 2008, 28(3), 216-221.

29. Bytnerowicz, A.; Omasa, K.; Paoletti, E. Integrated effects of air pollution and climate on forests: A northern hemisphere perspective. Environmental Pollution 2007 147, 438-445.

30. Paoletti, E.; Schaub, M.; Matyssek, R.; Wieser, G.; Augustaitis, A.; Bastrup-Birk, A.M.; Bytnerowicz, A.; Günthardt-Georg, M.S.; M’uller-Starck, G.; Serengil, Y. Advances of air pollution sciences: From forest decline to multiple stress effects on forest ecosystem services. Environmental Pollution 2010, 158, 1896-1989.

(C) 2015 by the authors; licensee MDPI, Basel, Switzerland. This article is an open access article distributed under the terms and conditions of the Creative Commons Attribution license (http://creativecommons.org/licenses/by/4.0/). 